\title{
Effects of ions traces on the dissolution of bioceramics composed of hydroxyapatite and $\beta$-tricalcium phosphate
}

\author{
Mohamed Jamil, Fatima Abida, Zineb Hatim*, Mostafa Elassfouri and Elhassan Gourri \\ Equipe Electrochimie et Biomatériaux, Faculté des Sciences, Departement de Chimie, \\ Université Chouaib Doukkali B.P. 20. El Jadida, Maroc
}

\begin{abstract}
The aim of this work is to study the effect of trace ions as $\mathrm{Mg}^{2+}, \mathrm{Sr}^{2+},\left(\mathrm{SiO}_{4}\right)^{4-}$ and $\mathrm{Al}^{3+}$, brought by the raw material, on the dissolution of the calcium-phosphate bioceramics. The precursor powders prepared by aqueous precipitation with molar ratio $\mathrm{Ca} / \mathrm{P}=1.630 \pm 0.002$, were calcined at $1100^{\circ} \mathrm{C}$ resulting in the formation of a mixture of hydroxyapatite $\left(\mathrm{Ca}_{10}\left(\mathrm{PO}_{4}\right)_{6}(\mathrm{OH})_{2}\right)$ and $\beta$-tricalcium phosphate $\left(\beta-\mathrm{Ca}_{3}\left(\mathrm{PO}_{4}\right)_{2}\right)$. Two mixtures which differ by the content of trace ions were characterized for phase purity, chemical composition and morphology. The dissolution tests were performed at $37{ }^{\circ} \mathrm{C}$ in acidic buffers solution at $\mathrm{pH} 4.8$. The results showed that the dissolution of calcium ions is more important in the presence of ions trace while the phosphor ions were not affected. The dissolution and dissolution-reprecipitation observed of various ions trace can modify the surface properties of calcium phosphate bioceramics and therefore the properties of biological products, such as resorbtion and reactivity can be affected.
\end{abstract}

Keywords : Bioceramics; hydroxyapatite; tricalcium phosphate; dissolution; ions trace.

\section{Introduction}

Currently, biomaterials based on calcium phosphate are increasingly used as synthetic bones substitutes in dentistry and medicine, due to the similarity of these materials to the composition of the mineral bones and their good biocompatibility ${ }^{1-8}$. Among of these biomaterials, we distinguish : hydroxyapatite $\left(\mathrm{Ca}_{10}\left(\mathrm{PO}_{4}\right)_{6}(\mathrm{OH})_{2}\right.$ : HAP, molar ratio $\mathrm{Ca} / \mathrm{P}=$ 1.667) with crystalline structure almost identical to the mineral structure of bones, the tricalcium phosphate $\left(\mathrm{Ca}_{3}\left(\mathrm{PO}_{4}\right)_{2}: \beta\right.$-TCP, molar ratio $\left.\mathrm{Ca} / \mathrm{P}=1.50\right)$ which has a high dissolution rate or still the biphasic mixture HAP / TCP $(1.52<\mathrm{Ca} / \mathrm{P}<1.667)$ that combines the physico-chemical properties of both compounds ${ }^{9-11}$. While, it is known that the solubility of bones substitutes is important, it allows the bone substitute to be gradually replaced by bones, by participating in their biodegradability. In general, the solubility of biphasic calcium phosphates is controlled by the HAP / TCP ratio ${ }^{12-14}$. However, no correlation was observed between the chemical composition of many commercial biomaterials and their dissolution ${ }^{15}$.

However, the in vitro dissolution characteristics of calcium phosphates are governed by a number of factors, which can be considered from two aspects: the in vitro environment and the properties of materials. The environmental factors include the type and the concentration 
of the buffered or unbuffered solutions; $\mathrm{pH}$; degree of saturation of solution, ions strength of solution, etc. The material properties include chemical composition, crystallinity, crystal particle size and purity ${ }^{16}$. The purpose of this paper is to highlight the influence of trace ions as $\mathrm{Mg}^{2+}, \mathrm{Sr}^{2+},\left(\mathrm{SiO}_{4}\right)^{4-}$ and $\mathrm{Al}^{3+}$ on the dissolution of calcium phosphates bioceramics of biological interest. These ions traces, brought by the raw material, are often detected during chemical controls of purity of such materials.

The present study employs the neutralization method to synthesize two calcium phosphorprecursor powder with $\mathrm{Ca} / \mathrm{P}$ molar ratio $1.630 \pm 0.002$. The precursor powders could be transformed to biphasic mixture of hydroxyapatite $\left(\mathrm{Ca}_{10}\left(\mathrm{PO}_{4}\right)_{6}(\mathrm{OH})_{2}(78 \%)\right)$ and $\beta$-tricalcium phosphate $\left(\beta-\mathrm{Ca}_{3}\left(\mathrm{PO}_{4}\right)_{2}(22 \%)\right)$ by heat-treating at $1100^{\circ} \mathrm{C}$. This ratio is considered as a good example of a bioactive and resorbed material. Two mixtures which differ by the content of trace ions were prepared using two commercialized grades of calcium hydroxide, while, the quality of phosphoric acid remains unchanged.

\section{Experimental Section}

\section{Synthesis of precursor powders by neutralization method}

Reference sample and trace ions incorporated calcium-phosphate powders were synthesized by reaction between the calcium hydroxide and orthophosphorique acid. The details of the method are described by F. Abida ${ }^{17}$. 0.995 mol of Calcium hydroxide $\left(\mathrm{Ca}(\mathrm{OH})_{2}\right)$ are dispersed under agitation in double distilled water $(0.6 \mathrm{~mol} / \mathrm{l})$. The orthophosphorique acid solution (1mol/l) was added into calcium hydroxide suspension using an automatic titration $(33 \mathrm{ml} / \mathrm{min})$ with a vigorous stirring $(500 \mathrm{Tour} / \mathrm{min})$. The molar ratio calcium/phosphor of the reagents is fixed at $1.630 \pm 0.002$. The reaction mixture is carried out at $22 \pm 0.1^{\circ} \mathrm{C}$ and the $\mathrm{pH}$ precipitation is from $7.5 \pm 0.2$. The precipitate powder was aged for $12 \mathrm{~h}$ then filtered and dried at $105^{\circ} \mathrm{C}$. The precursor powder could be transformed to biphasic mixture of hydroxyapatite and $\beta$-tricalcium phosphate by heat-treating at $1100^{\circ} \mathrm{C}$ for $3 \mathrm{~h}$.

Two mixture powders, which differ by the content of ion trace, have been prepared under the same conditions using two commercialized grades of calcium hydroxide, while the quality of phosphoric acid remains unchanged (Merck 85\%). The sample prepared with raw material with pharmaceutical grade (Panreac 98\%) will be designated as HAP, while the reference sample prepared under the same conditions with raw material with analytical grade (Merck 99 $\%)$ will be designated as HAPr.

\section{Dissolution tests}

The dissolution tests were carried out under acidic medium (similar to the process of acidification of the extracellular environment of osteoclasts) at $\mathrm{pH}$ close to $4.8 \pm 0.2$ involved by the in vivo degradation of the phosphocalcic implants ${ }^{18-20}$. The calcined powder was manually ground, and the particles less than $125 \mu \mathrm{m}$ were separated by sieving. $200 \mathrm{mg}$ of each sample was individually soaked in $100 \mathrm{ml}$ of buffer solution of acetic acid-sodium acetate $(\mathrm{pH}=4.8 \pm 0.2)$ at constant temperature of $37.0 \pm 0.1^{\circ} \mathrm{C}$ for fixed periods of time. The solution was kept under mechanical agitation and at sufficient speed to keep all the grains in suspension. At the end of each period, the liquid phase was separated and analyzed.

\section{Powders characterization}

Our calcined powders at $1100^{\circ} \mathrm{C}$ were examined by various analytical techniques. The identification of different crystal phases were determined by X-ray diffraction (Siemens 
Diffractometer D5000). Chemical analyses were performed by Inductively Coupled PlasmaAtomic Emission Spectroscopy (ICP-AES, Thermo Jarrell Ash, Atom Scan 16) analysis. Specific surface area was evaluated by the method Brunauer-Emmett-Teller (BET: Micromeritics ASAP 2010) based on the nitrogen adsorption on the surface of the material Pycnometer helium. The micro-structure of each powder was examined by scanning electron microscopy.

\section{Results and Discussion}

\section{Powders characterization}

Chemical analysis was carried out on reference sample (HAPr) and on the sample with ions trace (HAP). The ions trace concentrations and the calculated $\mathrm{Ca} / \mathrm{P}$ molar ratio are listed in Table 1. Both samples have a molar ratio of $1.630 \pm 0.002$. The total mass fraction of the trace ions was $1808 \mathrm{ppm}$ for the HAP sample. Other trace ions as $\mathrm{Fe}^{2+}, \mathrm{Zn}^{2+}, \mathrm{Al}^{3+} \ldots$ were detected, but with concentrations of less than $10 \mathrm{ppm}$. The same trace elements were detected in the reference sample (HAPr) but with total mass fraction from $320 \mathrm{ppm} . \mathrm{Mg}^{2+}$ and $\mathrm{Sr}^{2+}$ ions are brought by the calcium dihydroxide while the $\mathrm{Na}^{+}$and $\left(\mathrm{SO}_{4}\right)^{-}$are brought by orthophosphorique acid and calcium dihydroxide. The details of chemical analysis of raw materials are reported by $\mathrm{F}$. Abida ${ }^{17}$.

Table 1. Elemental traces analysis of the calcined powders.

\begin{tabular}{cccccccc} 
Sample & $\mathrm{Ca}(\%)$ & $\mathrm{P}(\%)$ & $\mathrm{Ca} / \mathrm{P}($ Molar ratio) & $\mathrm{Mg}(\mathrm{ppm})$ & $\mathrm{Sr}(\mathrm{ppm})$ & $\mathrm{Si}(\mathrm{ppm})$ & $\mathrm{Al}(\mathrm{ppm})$ \\
\hline HAP & $38.27 \pm 0.54$ & $18.22 \pm 0.22$ & $1.628 \pm 0.002$ & 937 & 122 & 543 & 206 \\
\hline HAPr & $38.48 \pm 0.54$ & $18.29 \pm 0.22$ & $1.630 \pm 0.002$ & 106 & 116 & 53 & 45 \\
\hline
\end{tabular}

The XRD patterns for both samples are presented in figure 1. The results showed that for two samples the calcined powders are consisted of mixture HAP and $\beta$-TCP phases. The transformation reaction by heat-treating can be schematically written as:

$$
\mathrm{Ca}_{10-\mathrm{x}}\left(\mathrm{HPO}_{4}\right)\left(\mathrm{PO}_{4}\right)_{6-\mathrm{x}}(\mathrm{OH})_{2-\mathrm{x}} \longrightarrow(1-\mathrm{x}) \mathrm{Ca}_{10}\left(\mathrm{PO}_{4}\right)_{6}(\mathrm{OH})_{2}+\mathrm{xCa}_{3}\left(\mathrm{PO}_{4}\right)_{2}(\beta),
$$

in agreement with the chemical analyzes $\mathrm{x}=0.22 \pm 0.02$.
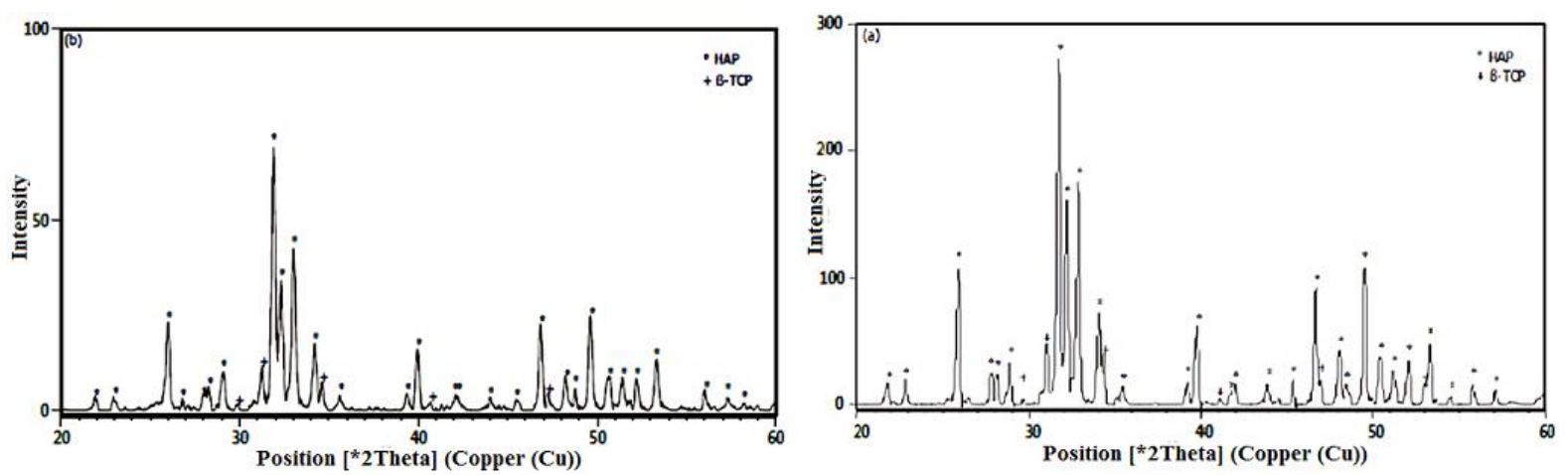

Fig. 1. XRD patterns of the sample (a) HAP and (b) HAPr.

SEM images of the samples are illustrated in Figure 2. Observations by electron microscopy showed that the morphology of the compared samples was similar. The samples are characteristic of agglomerates of spherical particles with specific area of close values 0.3 
and $0.5 \pm 0.2 \mathrm{~m}^{2} / \mathrm{g}$. The presence of trace elements had no significant effect on the morphology of the coatings.
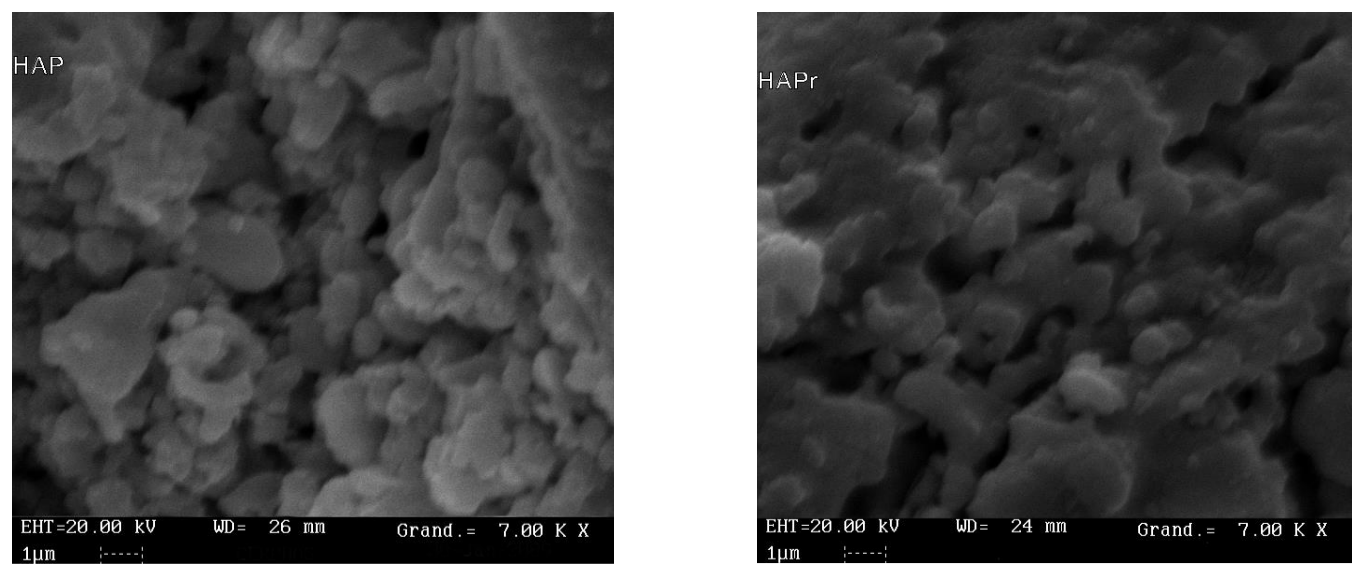

Fig. 2. Scanning electron micrograph of the samples HAP and HAPr.

\section{Dissolution Study}

\section{Release of calcium and phosphor}

Dissolution-reprecipitation behaviours of Calcium-phosphates are usually evaluated by measuring the $\mathrm{Ca}^{2+}$ and $\left(\mathrm{PO}_{4}\right)^{3-}$ ion concentration with soaking time ${ }^{16,23}$. Figure 4 showed the variation of $\mathrm{Ca}^{2+}$ and $\left(\mathrm{PO}_{4}\right)^{3-}$ ionic concentrations against immersion time in buffer solution of the reference sample and sample with ion traces. The results showed for both samples the dissolution of $\mathrm{Ca}^{2+}$ and $\left(\mathrm{PO}_{4}\right)^{3-}$ in the soaking solution. The rapid dissolution of the HAP and HAPr may be due to the acidic $\mathrm{pH}$ of the solution and also to the high solubility of tricalcium phosphate compared to the solubility of hydroxyapatite. (Solubility at $25{ }^{\circ} \mathrm{C},-\log (\mathrm{Ks})$, $\left(\beta-\mathrm{Ca}_{3}(\mathrm{PO} 4)_{2}, 28.9\right),\left(\mathrm{Ca}_{10}\left(\mathrm{PO}_{4}\right)_{6}(\mathrm{OH})_{2}, 116.8\right)$.

The dissolution of calcium ions is more important in the presence of ions trace while the phosphore ions were not affected by their presence. The dissolution of two sample is incongruent, showing a $\mathrm{Ca} / \mathrm{P}$ molar ratio in solution less than 0.5 .

The dissolution of calcium phosphate bioceramics can be controlled by processing on the crystals surface or by the transportating ions from the surface into the bulk solution ${ }^{24}$. In the acidic medium, dissolution is controlled at the surface by the formation of a complex derived from the hydrolysis of phosphates $\left(\mathrm{Ca}_{2}\left(\mathrm{HPO}_{4}\right)(\mathrm{OH})_{2}\right.$ or $\left.\mathrm{Ca}\left(\mathrm{HPO}_{4}\right), 2 \mathrm{H}_{2} \mathrm{O}\right)$. The initial stages of dissolution consist of calcium detachment from the surface and incorporation of protons instead. Orthophosphate groups are assumed to keep their positions without any relocation 25,26. The schematic depiction of a crystal surface is shown in Figure 3. Due to the fact, that calcium occupies definite lattice positions, whereas protons are bound to oxygen ions of orthophosphate groups, removing of each calcium results in decreasing of attraction forces between the nearest (to this calcium) orthophosphate group and rest part of the crystals. When all neighboring cations of calcium have been removed, orthophosphate groups (as $\mathrm{H}_{2} \mathrm{PO}_{4}^{-}, \mathrm{CaH}_{2} \mathrm{PO}_{4}+$ or $\mathrm{H}_{3} \mathrm{PO}_{4}{ }^{-}$) can also detach from the surface. Then they diffuse along the surface away from the dissolution steps before entering the solution as in the case of calcium $^{21,22}$.

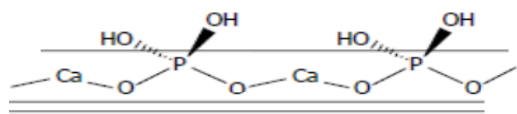

Figure 3. Ceramics surface sites appearing in aqueous acidic solution. 
The results of figure 4 also show that the dissolution of calcium and phosphore has been limited after one hour of immersion for reference sample. Indeed in buffer solution the ceramics has been dissolved, by ionic detachment of calcium and orthophosphate ions from the surface to the solution and some amount of ions is returned from the solution and adsorbed back onto the surface of ceramics which limits the phenomenon of dissolution.

For all immersion periods, the ionic concentration of calcium released in the soaking solution from the sample with trace elements is significantly greater than that released by reference sample. For example, the sample with more trace elements released $276 \mathrm{mg} / \mathrm{l}$ of $\mathrm{Ca}^{2+}$ for $1 \mathrm{~h}$ of immersion, while the reference sample released $174 \mathrm{mg} / \mathrm{l}$.

The results suggest that trace ions can affect solubility of calcium-phosphate bioceramics and, as a consequence, ion release. For acidic dissolution and in presences of ion traces, faster (or in a greater ionic proportion) dissolution of calcium when compared to that of orthophosphate. In this case, a surface layer of acidic orthophosphates, presence of HPO42ions and/or Ca-depleting of the surface may be suggested.
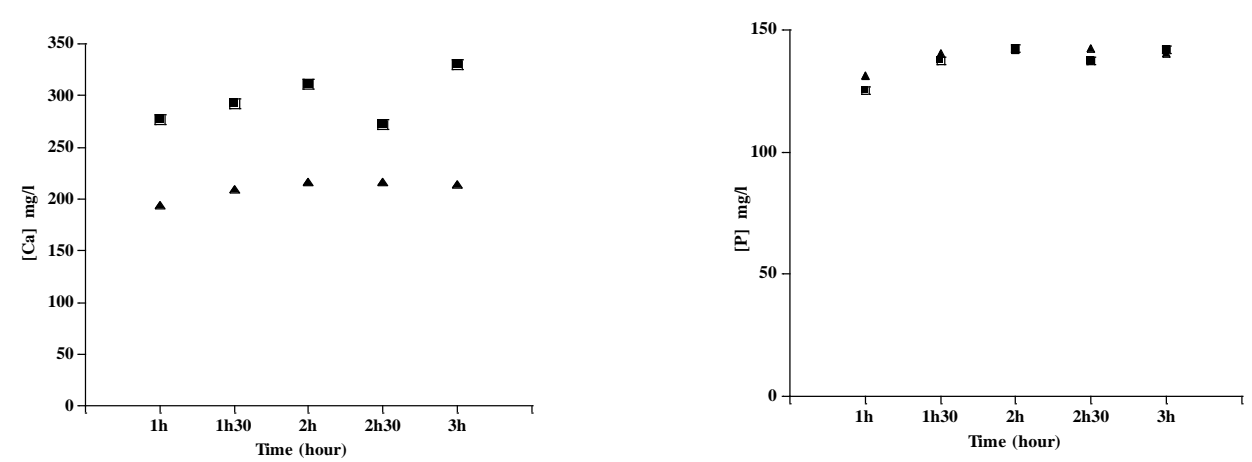

Figure 4. Dissolution of HAP $\boldsymbol{\square}$ and HAPr $\boldsymbol{\Delta}$ against immersion time: rate of calcium and phosphate

\section{Release of ions trace}

Variation of ionic concentrations of trace elements $\left(\mathrm{Mg}^{2+}, \mathrm{Sr}^{2+},\left(\mathrm{SiO}_{4}\right)^{4-}\right.$ and $\left.\mathrm{Al}^{3+}\right)$ against immersion time of the samples HAP and HAPr are shown in Figure 5. For both samples the released for all trace ions is observed at the beginning of immersion.

The ionic concentrations of trace elements released into the soaking solution didn't have the same variation against immersion time. At the beginning of immersion for both samples, dissolution of $\mathrm{Mg}^{2+}$ and $\mathrm{Al}^{3+}$ increased rapidly, while after 1hour of immersion the concentration of $\mathrm{Mg}^{2+}$ and $\mathrm{Al}^{3+}$ decreased gradually, $\left(\mathrm{SiO}_{4}\right)^{4-}$ and $\mathrm{Sr}^{2+}$ were released and remained in the medium. The decrease of concentrations can be explained by a precipitation of a new phase containing $\mathrm{Mg}^{2+}, \mathrm{Al}^{3+}$ and probably phosphorus ions. The decrease in $\mathrm{Mg}$ amount over time can also results in precipitation of whitlockite $\left(\mathrm{Ca}_{18} \mathrm{Mg}_{2} \mathrm{H}_{2}\left(\mathrm{PO}_{4}\right)_{14}\right)$ on the solid surface. This phenomenon was already observed by Legeros and all $^{27}$. The dissolutionreprecipitation phenomenon observed for some traces may modify the surface properties of the granules of calcium phosphate.

The results also show that contrary to the other ions, the concentration of $\mathrm{Sr}^{2+}$ released by the reference sample was greater than that released by sample with ions trace. This result can be explained by substitution of $\mathrm{Ca}^{2+}$ by $\mathrm{Mg}^{2+}$ in the case of the sample which contains a high concentration of $\mathrm{Mg}^{2+}(937 \mathrm{ppm})$, while a higher substitution of $\mathrm{Ca}^{2+}$ by $\mathrm{Sr}^{2+}$ in the case of the reference sample containing $\mathrm{Mg}^{2+}$ in a low concentration (106ppm). The competition of substitution between $\mathrm{Mg}^{2+}$ and $\mathrm{Sr}^{2+}$ is due to the difference of ionic radius of $\mathrm{Mg}^{2+}(72 \mathrm{pm})$ and $\mathrm{Sr}^{2+}(113 \mathrm{pm})$. 
During heat treatment of calcium phosphate bioceramics, some trace elements incorporated in HAP phase and others in $\beta$-TCP phase. Some studies have indicated that $\mathrm{Ca}$ atoms are substituted by $\mathrm{Mg}$ in the $\beta$-TCP, and not in the HAP phase ${ }^{28}$. Other ions trace can also be incorporated in phase $\beta$-TCP, While the strontium ions may be substituted by calcium ions in both HAP and $\beta$-TCP phases ${ }^{29}$.

The substitution of trace elements can modify the dissolution properties of tricalcium phosphate and calcium hydroxyapatite ${ }^{30}$. H. B. Pan reported that the solubility of bioceramics phosphocalcic substituted by $\mathrm{Sr}^{2+}$ increases with increasing $\mathrm{Sr}^{2+}$ content ${ }^{31}$. Porter and Patel observed that the dissolution of bioceramics substituted silicon increases with increasing silicon content ${ }^{30}$.

Heat treatment and incorporation of trace ions will induce surface irregularities and structural defects in the surface and inside the bulk of calcium phosphate crystals. In principle any surface irregularities may act as dissolution nuclei. These phenomena are responsible for the strong dissolution of calcium in the case of the sample containing traces ions. In vivo studies of ions incorporated in the calcium phosphate bioceramics showed that ions such as silicon, magnesium, strontium have an influence on the biological properties. Indeed, the nucleation and growth of calcium-apatite in biological systems occur in an environment rich in ions. These ions can affect both the kinetics and the thermodynamics of crystallization, and then the stability and the resorbability of calcium apatite ${ }^{32,33}$. These considerations highlight the general need of more detailed analyses of ion-substituted HAP in terms of modifications of the structural, morphological and chemical characteristics of the HAP induced by the ion. It follows that the study of the purity and of the ionic substitution in HAP is relevant for several reasons, including a better understanding of control of the properties of the precipitated phase and delivery of ions able to modify the nucleation and growth of bone.
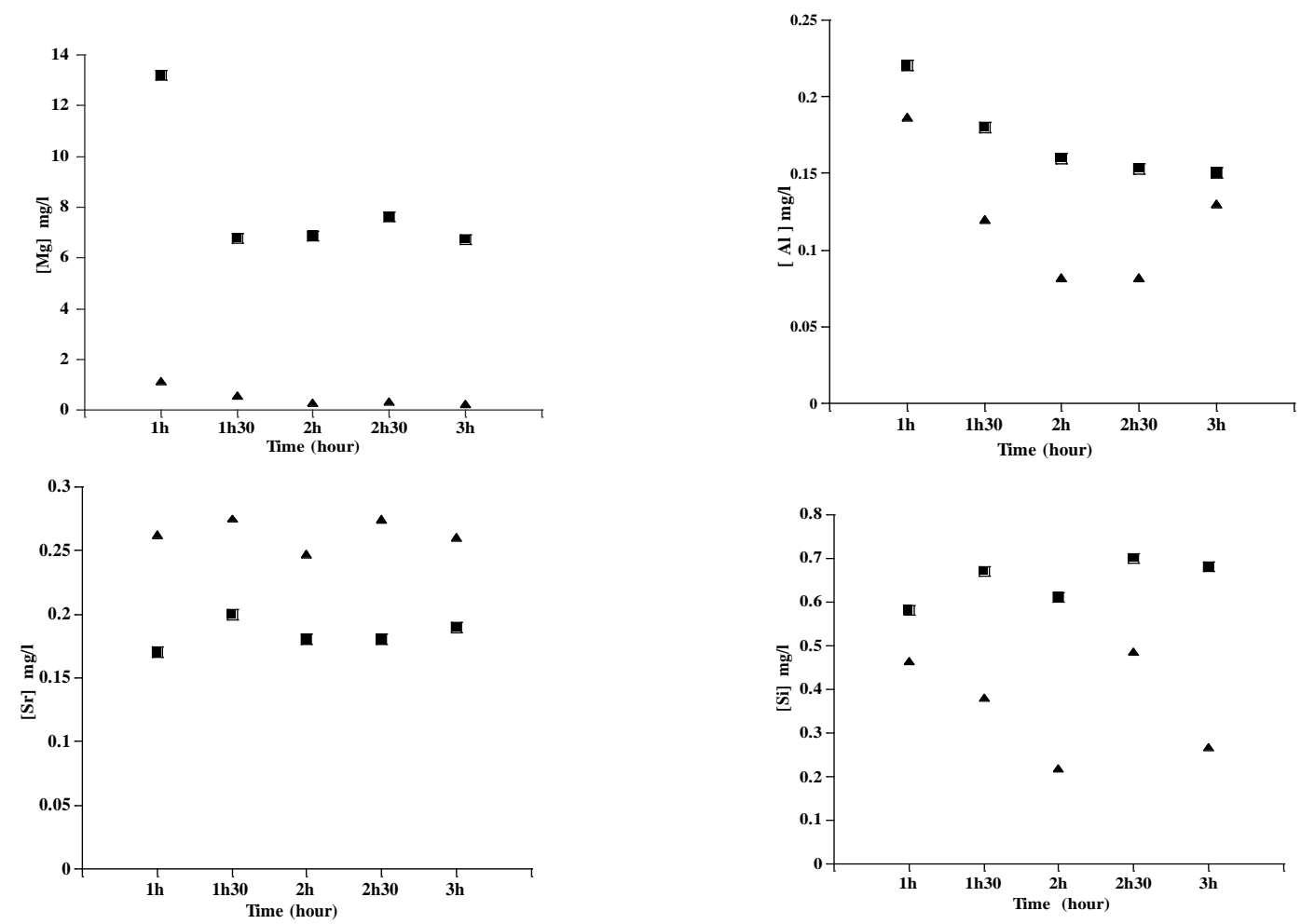

Figure 5. Dissolution of HAP $\boldsymbol{\square}$ and HAPr $\boldsymbol{\Delta}$ against immersion time: rate of $\mathrm{Mg}^{2+}, \mathrm{Al}^{3+}$, $\left(\mathrm{SiO}_{4}\right)^{4-}$ and $\mathrm{Sr}^{2+}$. 
We can conclude that ions traces can modify the structural, morphological and chemical properties of calcium phosphate bioceramics and consequently the solubility and biological properties as resorbability and reactivity can be change.

\section{Conclusion}

Dissolution of bioceramics consisted of a mixture of hydroxyapatite and $\beta$-tricalcium phosphate, which differs by the amount of trace ions has been studied. The results showed that the dissolution of bioceramics with ions traces was greater than the reference sample. Ions trace can modify the surface properties of calcium phosphate bioceramics and therefore the properties of biological products, such as resorbability and reactivity can be affected. Therefore, it could be noted that a necessary control of granular property and solubility of the calcium phosphate biomaterials should be estabilished before using theme in medical applications.

\section{References}

1- R. Cavagna, G. Daculsi, JM. Bouler, J Long Term Eff Med Implants, 1999, 9, 403-12.

2- A. Ransford, T. Morley, M. Edgar, P. Webb, N. Passuti, D. Chopin, et al., J Bone Joint Surg Br, 1998, 80, 13-8.

3- EB. Nery, KL. Lynch, WM. Hirthe, KH. Mueller, J Periodontol, 1975, 46, 328-47.

4- C. Rey, Biomaterials, 1990, 11, 13-5.

5- JC. Le Huec, D. Clement, E. Lesprit, J. Faber, Eur J Orthop Surg Traumotol, 2000, 10, 223-229.

6- N. Passuti, J. Delecrin, F. Gouin, D. Heymann, Encycl Med Chir (Elsevier, Paris), Appareil locomoteur, 1999, 14-015-B-10, 1-6.

7- S. Bruder, B. Fox. Clin Orthop, 1999, 367S, 68-83.

8- O. Gauthier, J-M. Bouler, E. Aguado, P. Pilet, G. Daculsi. Biomaterials, 1998, 19, 133-9.

9- S. Yamada, D. Heymann, J-M. Bouler, G. Daculsi, Biomaterials, 1997, 18, 1037-41.

10- J.C. Elliott, Elsevier, Amsterdam, 1994.

11- C.P.A.T. Kelein J. Biomed, Mater. Res., 1984, 18, 845-859.

12- G. Daculsi, R.Z. Legeros, E. Nery, K. Lynch et B. Kerebel, J. Biomed. Mater. Res., 1989, 23, 8, 883-94.

13- P. Frayssinet, J.L. Trouillet, N. Rouquet, E. Azimus et A. Autefage, Biomaterials, 1993, 14, 6, 423-9.

14- E.B. Nery, R.Z. Legeros, K.L. Lynch et K. J. Lee, Periodontol. 1992, 63, 9, 729-35.

15- L. Obadia, F. Triaud, C. Dupas, P. Pilet, B. Lamy, J.M. Bouler, G. Grimandi, ITBMRBM, 2005, $26,312-318$.

16- S. Sanchez-Salcedro, B.Balas, I. Izquierdo-Barba, M.Vallet-Regi, Acta Biomater Eng. Mater., 2005, 284, 281-284.

17- F. Abida, dissertation, Ph.D, UCD, Maroc, 2011.

18- P. Frayssinet, N. Rouquet, T. Tourenne, J. Fages, D. Hardy, G. Bonel, Cells and Materials, 1993, 3(4):383-94.

19- L. Brisson, S.J. Reshkin, J. Goré, S. Roger. European Journal of Cell Biology, 2012, 91, 847-860.

20- R. Riihonen , C.T. Supuran , S. Parkkila, S. Pastorekova, H.K. Väänänen, T. LaitalaLeinonen, Bone, 2007, 40, 1021-1031. 
21- J. Zhang, GH. Nancollas, J Phys Chem, 1994, 98, 1689-1694.

22- J. Zhang, GH. Nancollas, J Phys Chem, 1992, 96, 5478-5483.

23- S.L. Zhu, X.J. Yang, Z.D. Cui, J. Alloys Compd, 2010, 504, S168-S171.

24- SV. Dorozhkin, A review of literature World J Methodol February, 2012, 26; 2(1): 1-17.

25- SV. Dorozhkin, J Colloid Interface Sci, 1997, 191: 489-497.

26- SV. Dorozhkin, Comments Inorg Chem, 1999, 20: 285-299.

27- X. Liu, A. Ito, X. Wang, R.Z. Legeros, Acta, Biomaterialia, 2009, 5, 508-517.

28- S. Gomes, G. Renaudin, E. Jallot, J. Nedelec, Applied Materials and Interfaces, 2009, 1 (2),505-513.

29- G. Renaudin, E. Jallot, J. M. Nedelec, J Sol-Gel Sci Technol, 2009, 51, 287-294.

30- A.E. Porter, N. Patel, J.N. Skepper, S.M. Best, W. Bonfield, Biomaterials, 2003, 24, 4609-4620.

31- HB. Pan, Z.Y. Li, W.M. Lam, J.C. Wong, B.W. Darvell, K.D.K. Luk, W.W. Lu , Acta Biomater, 2009, 5, 1678-1685.

32- L. Wang, GH. Nancollas. Chem Rev, 2008, 108, 4628-69.

33- E. Boanini, M. Gazzano, A. Bigi, Acta Biomaterialia, 2010, 6, 1882-1894. 